\title{
One-month immunotherapy trial in treatment-failed TB patients
}

\author{
Olga V. Arjanova ${ }^{1}$, Dmitry A. Butov ${ }^{2}$, Natalia D. Prihoda ${ }^{1}$, Svetlana I. Zaitzeva $^{2}$, \\ Larisa V. Yurchenko ${ }^{1}$, Nina I. Sokolenko ${ }^{1}$, Anna L. Stepanenko ${ }^{2}$, Tatyana S. Butova ${ }^{2}$, \\ Elena A. Grinishina ${ }^{3}$, Olga A. Maksimenko ${ }^{4}$, Vichai Jirathitikal ${ }^{5}$, Aldar S. Bourinbaiar ${ }^{6}$, \\ Valery M. Frolov ${ }^{7}$, Galyna A. Kutsyna**
}

\footnotetext{
${ }^{1}$ Lisichansk Regional Tuberculosis Dispensary, Lisichansk, Ukraine;

${ }^{2}$ Department of Phtysiatry and Pulmonology, Kharkov National Medical University; Kharkov, Ukraine;

${ }^{3}$ Zmeev Regional Tuberculosis Dispensary, Zmeev, Ukraine;

${ }^{4}$ Izyum Regional Tuberculosis Dispensary, Izyum, Ukraine;

${ }^{5}$ Immunitor Thailand Co., LLC, Bangpakong Industrial Park, Chachoengsao, Thailand;

${ }^{6}$ Immunitor USA Inc., College Park, USA;

${ }^{7}$ Luhansk State Medical University, Luhansk, Ukraine; "kutsynagalyna@yahoo.com.
}

Received 17 August 2011; revised 1 September 2011; accepted 9 September 2011.

\section{ABSTRACT}

Treatment failed TB patients have very limited chances of survival. Open label trial of daily oral pill of V-5 Immunitor (V5) was conducted in 48 treatment-failed TB patients on palliative support consisting of isoniazid $(\mathrm{H})$ and rifampicin (R). The subjects had the following forms of TB; cavitary: disseminated: MDR-TB: DR-TB: TB/HIV at 35:13:7:4:1 ratio. After 1 month $62.5 \%$ of V5treated patients experienced negative sputum smear conversion $(P<0.0001)$, comprising 11 out of $12(91.7 \%)$ converted among those who had drug-resistant TB and TB/HIV. TB-associated inflammation was downregulated as evidenced by normalization of leukocytosis 7.4 vs. $6.7 \times 10^{9}$ $L(P=0.01)$ and decreased erythrocyte sedimentation rate 20.5 vs. $14.9 \mathrm{~mm} / \mathrm{h}(P<0.0001)$. The mean body temperature normalized from $37.25^{\circ}$ $\pm 0.6^{\circ}$ to $36.98^{\circ} \pm 0.4^{\circ}(P=0.0002)$. The average body weight gain and body mass index (BMI) increased by $0.8 \pm 0.7 \mathrm{~kg}$ and from 18.9 to 19.6 $\mathrm{kg} / \mathrm{m}^{2}$ respectively $(P<0.0001)$. Two patients (4.2\%) died from illicit drug- and alcohol-abuse related causes. No adverse effects or reactivation of disease due to immune intervention were seen at any time. V5 is safe and in combination with a simple two-drug regimen was highly effective as an immune adjunct to produce favorable outcome among treatment-failed and/ or drug-resistant TB patients.
Keywords: Biomarker; HIV; Inflammation; MDR-TB; Mycobacterium; Survival; Treatment Failure; Vaccine;

\section{INTRODUCTION}

Mycobacterium tuberculosis is responsible for the largest number of deaths attributable to a single microorganism. Nearly 9 million people develop TB each year and 2 million die from the disease [1]. Currently available chemotherapies for treatment of TB are not ideal they require multiple tuberculosis drugs to be taken for long periods of time. The length of therapy, coupled with side effects, often results in poor patient adherence, treatment failure, and the emergence of drug resistance [2]. Current so-called directly observed short-course (DOTS) chemotherapy requires 6 months; with isoniazid, rifampicin, pyrazinamide and ethambutol during first 2 months of intensive phase and isoniazid and rifampicin for continuation phase. The WHO global target for successful DOTS is set at $85 \%$ or higher, however the worsening epidemic of drug resistant TB converging with HIV reduces the likelihood of attaining this goal. Patients who failed treatment have very few therapeutic options and mortality and morbidity in this category is extremely high. If left untreated one year fatality estimate is $70 \%$ for smear-positive and $20 \%$ for culturepositive but smear-negative tuberculosis [2]. In a study involving patients resistant to isoniazid and rifampicin $65 \%$ became culture negative but treatment failure, defined as the inability of chemotherapy to sterilize cultures, occurred in almost half of patients (46\%) [3]. The idea that immunotherapy might improve TB treatment outcomes started gaining consensus in recent years [4]. 
Oral therapeutic vaccine V5 Immunitor was originally developed for the management of chronic hepatitis $\mathrm{B}$ and $C$ [5-7]. The preparation is derived from pooled blood of HBV- and HCV-positive donors, which following chemical- and heat inactivation was formulated into an oral pill according to the proprietary technology developed by us [7]. During clinical trial in 20 patients with hepatitis C, who happened to have pulmonary TB with HIV co-infection, V5 produced mycobacterial clearance in sputum smears of $94.4 \%$ of patients within one month [8]. Due to this surprising outcome a placebo-controlled, randomized phase $2 \mathrm{~b}$ trial was initiated. Two preliminary reports from this trial involving initial 88 patients were already published, confirming that V5 was safe and consistently enhanced the efficacy of TB drugs $[9,10]$.

In these trials we had a couple of patients who have repeatedly failed all available therapies and were on so-called palliative support consisting of isoniazid and rifampicin only [10]. Despite treatment failure and seemingly ineffective two-drug combination these patients became sputum smear negative within one month. In the present study we expanded this observation by recruiting 48 treatment-failure patients who received palliative $\mathrm{HR}$ in combination with V5 for one month.

\section{MATERIALS AND METHODS}

\subsection{V5 Immunitor}

V5 is derived from the pooled blood of donors with HBV and HCV, which after heat- and chemical inactivation was formulated into an oral pill [5-7]. It is well known that one third of people carry $M$. tuberculosis without showing symptoms of the disease-latent TB. Therefore, V5 inherently comprises circulating antigens of $M$. tuberculosis. As we had not known prior to this accidental discovery that V5 may affect TB we have no much information regarding the exact content of $M$. tuberculosis antigens. V5 was approved in 2008 by the Ministry of Health of Ukraine as an immunomodulating supplement for the management of chronic hepatitis.

\subsection{Patients}

The conduct of the trial was approved by the internal review board of the Lisichansk TB Dispensary and has a ClinicalTrials.gov identifier: NCT01222338. The study involved 48 patients all of whom were treatment failures and were placed on so-called palliative support consisting of daily isoniazid $(\mathrm{H})$ and rifampicin (R) (Table 1 and Figure 1). This regimen is assigned to very limited number of patients by the regional health authorities as a result of case-by-case evaluation of medical and treatment adherence history by specially appointed ethics committee. Usually these are patients who had repeatedly failed to convert after multiple treatment options had been tried unsuccessfully for an average/median (6 years \pm 3.3 years $/ 5$ years (range 2 years - 19 years). Drug and alcohol abuse combined with poor compliance are common among these patients. The participation in this study was voluntary and patients were eligible to enroll only after signing the written consent. The group had 4 females (8.3\%) and 44 males between ages 23 - 68 with mean \pm SD (median) age 38.4 years $\pm 10.9(35.5)$

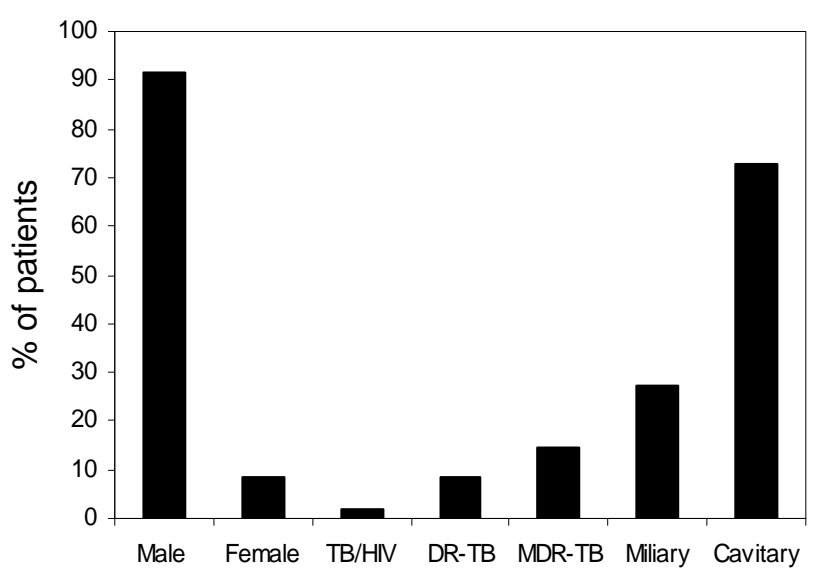

Figure 1. The proportion of patients at baseline according to their gender and diagnosis.

Table 1. Summary of baseline data and treatment outcome in 48 treatment-failed TB patients treated with isoniazid and rifampicin in combination with V5 for one month.

\begin{tabular}{|c|c|c|c|c|c|c|c|c|c|c|c|c|c|c|c|c|}
\hline \multirow{2}{*}{$\begin{array}{l}\text { Sex } \\
\text { F/M }\end{array}$} & \multirow{2}{*}{ Age } & \multirow{2}{*}{ Diagnosis } & \multicolumn{2}{|c|}{$\begin{array}{c}\text { Body } \\
\text { weight(kg) }\end{array}$} & \multicolumn{2}{|c|}{$\begin{array}{c}\text { Body mass } \\
\text { index }\left(\mathrm{kg} / \mathrm{m}^{2}\right)\end{array}$} & \multicolumn{2}{|c|}{$\begin{array}{c}\text { Body } \\
\text { temperture }\left({ }^{\circ} \mathrm{C}\right)\end{array}$} & \multicolumn{2}{|c|}{$\begin{array}{l}\text { Hemoglo- } \\
\text { bin(g/L) }\end{array}$} & \multicolumn{2}{|c|}{$\mathrm{ESR}(\mathrm{mm} / \mathrm{h})$} & \multicolumn{2}{|c|}{$\begin{array}{l}\text { Leukocytes } \\
\qquad\left(\times 10^{9} \mathrm{~L}\right)\end{array}$} & \multicolumn{2}{|c|}{$\begin{array}{l}\text { Sputumsmear } \\
\qquad(+/-)\end{array}$} \\
\hline & & & before & after & before & after & before & after & before & after & before & after & before & after & before & after \\
\hline \multirow{2}{*}{\multicolumn{2}{|c|}{$\begin{aligned} & \text { Mean } \\
& 38.4 \\
4 / 44 & \pm 10.9 \\
& \text { Median } \\
& 35.5\end{aligned}$}} & $\begin{array}{l}\text { Miliary TB = } 13 \\
\text { Cavitary TB = } \\
35\end{array}$ & $\begin{array}{c}57.8 \\
\pm 10.8\end{array}$ & $\begin{array}{c}58.6 \\
\pm 10.7\end{array}$ & $\begin{array}{l}18.9 \\
\pm 3\end{array}$ & $\begin{array}{c}19.7 \\
\pm 3\end{array}$ & $\begin{array}{c}37.25 \\
\pm 0.6\end{array}$ & $\begin{array}{c}36.98 \\
\pm 0.4\end{array}$ & $\begin{array}{c}118.8 \\
\pm 15\end{array}$ & $\begin{array}{l}118.5 \\
\pm 14.3\end{array}$ & $\begin{array}{c}20.5 \\
\pm 14.9\end{array}$ & $\begin{array}{c}14.9 \\
\pm 11.2\end{array}$ & $\begin{array}{c}7.4 \\
\pm 3.4\end{array}$ & $\begin{array}{c}6.7 \\
\pm 2.9\end{array}$ & $48 / 0$ & $18 / 30$ \\
\hline & & $\begin{array}{l}\text { MDR-TB }^{\mathrm{a}}=7 \\
\mathrm{DR}^{\mathrm{T}} \mathrm{TB}^{\mathrm{b}}=4 \\
\mathrm{~TB} / \mathrm{HIV}=1\end{array}$ & \multicolumn{2}{|c|}{$\mathrm{P}<0.0001$} & \multicolumn{2}{|c|}{$\mathrm{P}<0.0001$} & \multicolumn{2}{|c|}{$P=0.0002$} & \multicolumn{2}{|c|}{$P=0.78$} & \multicolumn{2}{|c|}{$\mathrm{P}<0.0001$} & \multicolumn{2}{|c|}{$P=0.013$} & \multicolumn{2}{|c|}{$\mathrm{P}<0.0001$} \\
\hline
\end{tabular}


years. Almost half of patients were underweight (47.9\% with BMI less than $18.5 \mathrm{~kg} / \mathrm{m}^{2}$ ), the baseline body weight and body mass index (BMI) ranged between 38 $\mathrm{kg}-86 \mathrm{~kg}$ and $14-26.5$ with mean \pm SD (median) 57.8 $\mathrm{kg} \pm 10.8$ (56.5) $\mathrm{kg}$ and $18.9 \mathrm{~kg} / \mathrm{m}^{2} \pm 3(18.6) \mathrm{kg} / \mathrm{m}^{2}$. This group had one confirmed HIV infection and 7 MDR-TB. Four additional patients had confirmed drug resistance other than MDR-TB (Table 1). For the remaining patients drug resistance profile was unavailable. Thirteen patients had disseminated or miliary form of TB (27.1\%) and the rest had cavitary disease (72.9\%). Most patients, 29 out of 48 (60.4\%), had normal body temperature at study initiation with overall mean \pm $\mathrm{SD} /$ median $37.3^{\circ} \mathrm{C} \pm 0.6^{\circ} \mathrm{C} / 36.8^{\circ} \mathrm{C}$.

\subsection{Laboratory Evaluation}

The sputum microscopy on acid-fast bacilli (AFB) smears was conducted in a blinded fashion at baseline and one month later. TB drug resistance was determined by commercially available kit (Tulip Diagnostics, Goa, India) in one third of patients. The failure to test every patient for drug resistance was due to lack of funds for laboratory services. MDR-TB status was assigned when resistance to both isoniazid and rifampicin, with or without resistance to other drugs, was present. DR-TB was assigned when resistance to drugs other than those in MDR-TB category was found. The hematology parameters were evaluated by standard routine techniques at baseline and repeated one month later.

\subsection{Statistical Analysis}

The obtained results were analyzed with commercially available statistical software (GraphPad Software Inc, La Jolla, CA, USA). The paired Student t-test was used to compare before-after means by assuming that the distribution of the differences was in accord with Gaussian distribution. The Wilcoxon test was used to compare paired before-after nonparametric values such as conversion rates arranged in "yes" or "no" binary manner. Fisher's exact two-tailed test was employed for analysis of data arranged in a contingency table. All statistical analyses were done on intent-to-treat basis, involving all initially enrolled patients including fatalities. The resulting probability values were considered as significant at $\mathrm{P} \leqslant 0.05$.

\section{RESULTS}

\subsection{Lack of Adverse Reactions}

During the entire duration of follow-up no adverse reactions or reactivation of $\mathrm{TB}$ attributable to V5 were identified. Quite contrary patients who were receiving chemotherapy along with V5 fared much better. Due to alcohol and narcotic drugs' overdose two patients in the
V5 group died during the study but they were not excluded from the statistical analysis of data, so that the intent-to-treat design was not compromised. The quantitative endpoints detailed below indicate that the addition of V5 to anti-tuberculosis therapy (ATT) has resulted in better clinical outcome.

\subsection{Effect On Axillary Body Temperature}

The average \pm SD (median) body temperature values were relatively low, i.e., $37.3^{\circ} \mathrm{C} \pm 0.6$ (36.8) ${ }^{\circ} \mathrm{C}$. The proportion of patients with low grade fever was also small, i.e., 39.6\%. At study initiation the proportion of patients who had normal body temperature of $36.8^{\circ} \mathrm{C}$ was $60.4 \%$ which one month later increased to $83.3 \%$ (Figure 2).The overall mean temperature drop was $0.3^{\circ} \mathrm{C}$, i.e., from $37.25^{\circ} \mathrm{C} \pm 0.6^{\circ} \mathrm{C}$ to $36.98^{\circ} \mathrm{C} \pm 0.4^{\circ} \mathrm{C}$ (P $=0.0002)$.

\subsection{Effect on Hematology Parameters}

The effect of V5 on white blood cells and hematology parameters are shown in Table $\mathbf{1}$ and Figure 2. Patients displayed following positive changes, which resulted from V5 intervention. Elevated leukocyte counts, traditionally associated with inflammation, were reduced in V5-treated group from 7.4 to $6.7 \times 10^{9} / \mathrm{L}(\mathrm{P}=0.013)$. The decrease was observed in 31 (64.6\%) patients, increase in 10 (20.8\%), and in remaining 7 (14.6\%) no changes relative to baseline were seen. Another marker of inflammation, the erythrocyte sedimentation rate (ESR), declined from 20.5 to $14.9 \mathrm{~mm} / \mathrm{h}(\mathrm{P}<0.0001)$. The favorable response was seen in 37 (77.1\%) individuals and in remaining 11 patients ESR increased. The content of hemoglobin has not changed, i.e., $118.8 \mathrm{~g} / \mathrm{L} \pm 15 \mathrm{~g} / \mathrm{L}$ vs. $118.5 \mathrm{~g} / \mathrm{L} \pm 14.3 \mathrm{~g} / \mathrm{L}(\mathrm{P}=0.78)$. Among these $39.6 \%$ of patients had favorable response, one $(2.1 \%)$ had unchanged level, and in remaining 28 (58.3\%) patients the hemoglobin content had decreased.

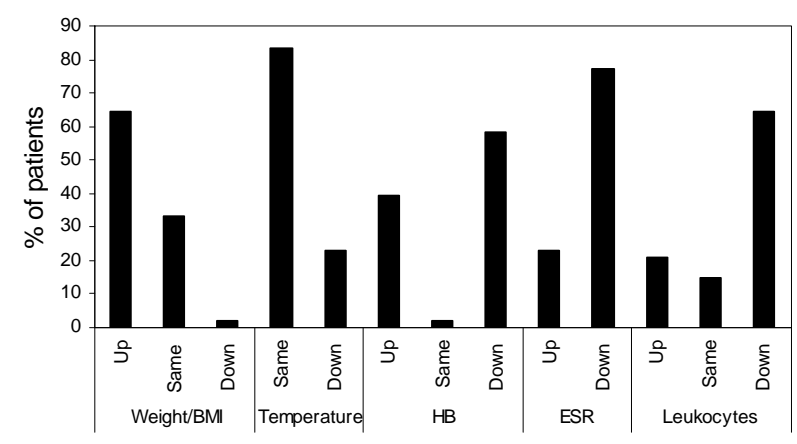

Figure 2. Proportion of patients with three types of outcome in relation to the weight/body mass index, body temperature, hemoglobin content (HB), erythrocyte sedimentation rate (ESR), and leukocyte counts. 


\subsection{Effect On Weight and Body Mass Index}

Enrolled patients had underweight problem. According to BMI almost half of enrolled patients (47.9\%) had entry level values below normal $18.5 \mathrm{~kg} / \mathrm{m}^{2}$; two (4.2\%) patients were overweight, and the rest were in the normal range between $18.6 \mathrm{~kg} / \mathrm{m}^{2}-25 \mathrm{~kg} / \mathrm{m}^{2}$. The mean/ median baseline weight and body mass index were 57.8 $\mathrm{kg} \pm 10.8 / 56.5 \mathrm{~kg}$ and $18.9 \mathrm{~kg} / \mathrm{m}^{2} \pm 3 / 18.6 \mathrm{~kg} / \mathrm{m}^{2}$ respectively. After one month one patient (2.1\%) lost $1 \mathrm{~kg}, 16$ patients $(33.3 \%)$ retained the same weight and in remaining 31 (64.6\%) patients the increase in body mass ranged between $1 \mathrm{~kg}$ - $2 \mathrm{~kg}$, with average (median) body weight accrual equal to $0.8 \mathrm{~kg} \pm 0.7$ (1.0) $\mathrm{kg}(\mathrm{P}<$ $0.0001)$. Changes in body mass index were identical to variations in the absolute bodyweight (Figure 2). After the month one patient lost $0.3 \mathrm{~kg} / \mathrm{m}^{2}, 16$ patients (33.3\%) retained same BMI, and in remaining 31 (64.6\%) patients the increase ranged between $0.2 \mathrm{~kg} / \mathrm{m}^{2}-0.9 \mathrm{~kg} / \mathrm{m}^{2}$, with average (median) gain equal to $0.27 \mathrm{~kg} / \mathrm{m}^{2} \pm 0.26$ (0.3) $\mathrm{kg} / \mathrm{m}^{2}$ reaching values considered to be in the normal range, i.e., $19.7 \pm 3$ (19.6) $(\mathrm{P}<0.0001)$.

\subsection{Effect on Mycobacterial Clearance}

Bacterial clearance was scored in a blinded fashion on AFB-stained sputum smears as negative/positive scores. At the end of first month thirty (62.5\%) of V5-treated patients became sputum negative, which was highly significant by paired Wilcoxon ranking test $(\mathrm{P}<0.0001)$. The majority of converted patients, 37 out of 48 (70.3\%) had cavitary TB, and remaining converters had disseminated TB. Eleven out of 12 (91.7\%) patients with MDR-TB, DR-TB and single TB/HIV had converted after one month. It is of interest that when treatment-failure patients have been stratified according to the duration of their disease, those who had longer TB history were converted more readily (Figure 3).

\section{DISCUSSION}

The results of this one-month immunotherapy study in treatment-failed TB patients on palliative support, consisting of isoniazid and rifampicin, revealed high negative sputum conversion rate. These results combined with additional benefit of enhanced body mass gain, fever normalization, and potent anti-inflammatory effect are in line with previously reported favorable responses due to V5 intervention [8-10]. The fact that we have seen negative conversion in patients who were unsuccessfully treated with first- and second-line chemotherapy for 6 years on average and were as a consequence given up is perhaps the most impressive outcome of this study.

As new TB drugs are still in pipeline, one of priorities in TB management is to find optimal combination among

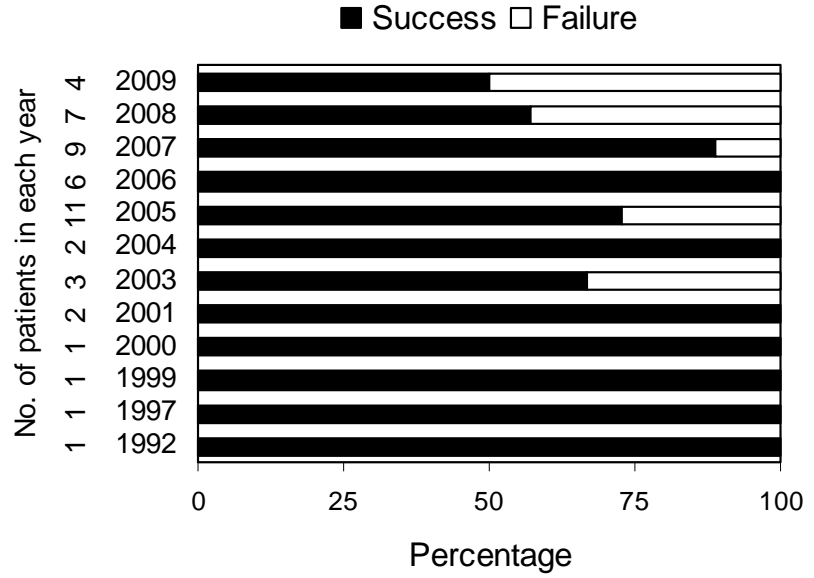

Figure 3. Proportion of V5-treated patients at study conclusion with negative (success) or positive (failure) sputum smear in relation to the year of TB diagnosis ( $\mathrm{Y}$ axis).

existing drugs [1,11]. Isoniazid and rifampicin tandem regimen, introduced in 1970's, is perhaps best effective and least toxic combination. However, when resistance to both drugs arises, treatment is complicated, prolonged, costly, and outcome is poor. TB treatment failure is strongly predictive of active MDR-TB and success rates are rarely better than $65 \%$ even when multiple $1^{\text {st }}$ and $2^{\text {nd }}$ line TB drugs are employed for as long as 12 months 24 months [3,12,13]. Recently reported DOTS success rate in former Soviet Union countries in TB patients, some of whom had MDR-TB and HIV, was 68.1\% [14]. However, not every patient enrolled in our study had lab results from drug-resistance testing. We had 7 and 4 confirmed MDR-TB and DR-TB respectively including one single patient with HIV; out of these 12 individuals 11 became sputum negative. Even if it may appear at first sight that we are obtaining similar proportion of conversion as in literature, our results are not comparable to prior studies since we were able to obtain such a conversion rate after one month instead of conventional 6 months - 24 months. This implies that immune-based therapy can contribute to faster favorable response even when the least-potent combination of TB drugs is employed, since by definition MDR-TB is refractory to this very same $\mathrm{H}$ and $\mathrm{R}$ combination. It is also of interest that all treatment-failure patients who had history of chronic TB longer than 10 years had converted. Due to small sample size the latter findings could have been a random event. Specially tailored, larger, longitudinal studies are required to determine the extent of the clinical benefit of V5, which according to our experience spanning over the last 4 years appears to be equally effective against treatment-refractory TB and drug-sensitive cases.

The weight accrual during TB therapy has been identified as a reliable anthropomorphic biomarker of favorable treatment outcome that could be readily utilized in 
resource-limited settings [15]. Bernabe-Ortiz et al., [ 16] have shown that after adjustment for baseline differences, patients with good outcome gained, after the first month of treatment, mean $0.9 \mathrm{~kg}(\mathrm{P}<0.001)$, whereas those with poor outcome lost $1.9 \mathrm{~kg}(\mathrm{P}=0.003)$. Present results with V5 closely match findings from Peru study suggesting that the trend in bodyweight can predict success of tuberculosis therapy. The correlation between body weight and BMI was not surprising either. Body mass index is equally reflective of severity of disease and is a risk factor closer associated with death than even MDR-TB diagnosis. Its improvement in parallel with weight gain indicates that the benefit of V5 therapy can be predicted by both categories of wasting measurement. Alcohol and substance abuse have been associated with poor TB outcome in many studies $[17,18]$ and was the cause of death in two patients during this study. We suspect that practically every patient in our group had this problem but the exact extent of abuse is not known since most patients were reluctant to disclose their addictions.

Leukocytosis and high erythrocyte sedimentation rate are common during active pulmonary TB [19]. These biomarkers of tuberculosis which reflect the inflammatory response have been predictable of outcome of V5 immunotherapy in this and prior studies. In our patient population favorable responses were seen when values of both markers declined. These results are further supported by the effect of V5 on defervescence. In contrast, the hemoglobin content, which does not seem to be related to inflammation, has not been affected by V5.

It has been commonly argued that immunotherapy can boost TB drugs' activity and shorten treatment duration [4,20-23]. As conventional TB drugs have been of little value in failure cases are there immune-based intervenetions that were successful in such a situation? The search of the medical literature failed to produce any noteworthy evidence except our own published study in which 40 end-stage patients with TB and HIV were treated with multi-herbal immunomodulator, Dzherelo (Immunoxel) [24]. This intervention resulted in $65 \%$ negative sputum conversion rate as opposed to $5 \%$ in the control. Despite best possible care 6 patients had died in Immunoxel arm. Remaining 14 patients experienced clinical improvements and one patient was discharged due to full recovery. Among 20 matched subjects on conventional TB regimen, 12 died and only one had shown some clinical improvement ( $\mathrm{P}=0.001$; OR 2.6 at $95 \%$ CI $1.5-4.7)$. While patient population in that study was not comparable to ours and sample sizes were small, we and our collaborators in Ukraine have worked on immunotherapy of TB and HIV over the past 10 years, which resulted in a dozen published trials involving about 1,200 individuals [25]. This extensive experience is summarized as follows. Typical sputum conversion rate among MDR,
XDR and TB/HIV patients after 2 months - 4 months of herbal immunotherapy was in $85 \%-100 \%$ range, while in chemotherapy controls it took 6 months - 24 months to reach $48 \%-85 \%$. What is remarkable is that very same clinical manifestations, i.e., inflammation, fever, and wasting improved in a manner strikingly similar to V5. This suggests to us that a successful immunotherapy of any kind ought to produce clinical response that displays similar, if not identical trend, with these endpoints. This conclusion is supported by results of numerous trials of Mycobacterium vaccae, the WHO recommended immunotherapy for TB [4], in which sputum conversion was invariably accompanied by weight gain and decreased ESR [26].

Despite many limitations of this study it is clear that the combination of V5 with stripped-down TB regimen, consisting of isoniazid and rifampicin only, produces favorable outcome in treatment-failed TB including drug-resistant TB and TB/HIV. V5 was safe; no reactivation of TB was seen at any time, which perhaps is due to potent anti-inflammatory activity. Immune intervention such as V5 needs to be tried independently by investigators in other countries so that simple and safe treatment for TB is available sooner, especially to those who have exhausted all treatment options.

\section{ACKNOWLEDGEMENTS}

We thank all volunteers who participated in this study. The wholehearted support of clinicians, nurses and lab personnel who contributed their effort made this study possible. Our gratitude is expressed to too-many-to-list experts in TB who kindly shared with us their opinions and critiques prior to and after this study was completed.

\section{REFERENCES}

[1] Lienhardt, C., Vernon, A. and Raviglione, M.C. (2010) New drugs and new regimens for the treatment of tuberculosis: Review of the drug development pipeline and implications for national programmes. Current Opinion in Pulmonary Medicine, 16, 186-193. doi:10.1097/MCP.0b013e328337580c

[2] Tiemersma, E.W., van der Werf, M.J., Borgdorff, M.W., Williams, B.G. and Nagelkerke, N.J. (2011) Natural history of tuberculosis: duration and fatality of untreated pulmonary tuberculosis in HIV negative patients: A systematic review. PLoS One, 6, e17601. doi:10.1371/journal.pone.0017601

[3] Goble, M., Iseman, M.D., Madsen, L.A., Waite, D., Ackerson, L. and Horsburgh, C.R. Jr. (1993) Treatment of 171 patients with pulmonary tuberculosis resistant to isoniazid and rifampin. New England Journal of Medicine, 328, 527-532. doi:10.1056/NEJM19930225328080

[4] Churchyard, D.J. (2007) Report of the expert consultation on immunotherapeutic interventions for tuberculosis. TDR/World Health Organization, Geneva, Switzerland. 
http://apps.who.int/tdr/publications/tdr-research-publicati ons/immunotherapeutic-interventions-tb/pdf/intervention s-tb.pdf

[5] Batdelger, D., Dandii, D., Jirathitikal, V. and Bourinbaiar, A.S. (2007) Open label trial of therapeutic hepatitis B vaccine V-5 Immunitor (V5) delivered by oral route. Letters in Drug Design and Discovery, 4, 540-544, 2007. doi:10.2174/157018007782794545

[6] Batdelger, D., Dandii, D., Jirathitikal, V. and Bourinbaiar, A.S. (2008) Open label trial of therapeutic immunization with oral V-5 Immunitor (V5) vaccine in patients with chronic hepatitis C. Vaccine, 26, 2733-2737. doi:10.1016/j.vaccine.2008.03.021

[7] Batdelger, D., Dandii, D., Dahgwahdorj, Ya., Erdenetsogt, E., Oyunbileg, J., Tsend, N., Bayarmagnai, B., Jirathitikal, V. and Bourinbaiar, A.S. (2009) Clinical experience with therapeutic vaccines designed for patients with hepatitis. Current Pharmaceutical Design, 15, 1159-1171. doi:10.2174/138161209787846793

[8] Arjanova, O.V., Prihoda, N.D., Yurchenko, L.V., Sokolenko, N.I., Frolov, V.M., Tarakanovskaya, M.G., Jirathitikal, V. and Bourinbaiar, A.S. (2010) Phase 2 trial of V-5 Immunitor (V5) in patients with chronic hepatitis $\mathrm{C}$ co-infected with HIV and Mycobacterium tuberculosis. Journal of Vaccines and Vaccination, 1, 103. doi:10.4172/2157-7560.1000103

[9] Butov, D.A., Pashkov, Y.N., Stepanenko, A.L., Choporova, A.I., Butova, T.S., Batdelger, D., Jirathitikal, V., Bourinbaiar, A.S. and Zaitzeva, S.I. (2011) Phase IIb randomized trial of adjunct immunotherapy in patients with first-diagnosed tuberculosis, relapsed and multidrug-resistant (MDR) TB. Journal of Immune Based Therapies and Vaccines, 9, 3. doi:10.1186/1476-8518-9-3

[10] Arjanova, O.V., Prihoda, N.D., Yurchenko, L.V., Sokolenko, N.I., Frolov, V.M., Tarakanovskaya, M.G., Batdelger, D., Jirathitikal, V. and Bourinbaiar, A.S. (2011) Adjunct oral immunotherapy in patients with re-treated, multidrug-resistant or HIV-coinfected TB. Immunotherapy, 3, 181-191. doi:10.2217/imt.10.96

[11] Nuermberger, E.L., Spigelman, M.K. and Yew, W.W. (2010) Current development and future prospects in chemotherapy of tuberculosis. Respirology, 15, 764-778. doi:10.1111/j.1440-1843.2010.01775.x

[12] Becerra, M.C., Freeman, J., Bayona, J., Shin, S.S., Kim, J.Y., Furin, J.J., Werner, B., Sloutsky, A., Timperi, R., Wilson, M.E., Pagano, M. and Farmer, P.E. (2000) Using treatment failure under effective directly observed short-course chemotherapy programs to identify patients with multidrug-resistant tuberculosis. International Journal of Tuberculosis and Lung Diseases, 4, 108-114. PMid:10694087

[13] Johnston, J.C., Shahidi, N.C., Sadatsafavi, M. and Fitzgerald, J.M. (2009) Treatment outcomes of multidrugresistant tuberculosis: a systematic review and metaanalysis. PLoS One, 4, e6914. doi:10.1371/journal.pone.0006914

[14] Faustini, A., Hall, A.J. and Perucci, C.A. (2005) Tuberculosis treatment outcomes in Europe: a systematic review. European Respiratory Journal, 26, 503-510. doi:10.1183/09031936.05.00103504

[15] Khan, A., Sterling, T.R., Reves, R., Vernon, A. and Horsburgh, C.R. (2006) Lack of weight gain and relapse risk in a large tuberculosis treatment trial. American Journal of Respiratory and Critical Care Medicine, 174, 344-348. doi:10.1164/rccm.200511-1834OC

[16] Bernabe-Ortiz, A., Carcamo, C.P., Sanchez, J.F. and Rios, J. (2011) Weight variation over time and its association with tuberculosis treatment outcome: a longitudinal analysis. PLoS One, 6, e18474.

doi:10.1371/journal.pone.0018474

[17] Zafran, N., Heldal, E., Pavlovic, S., Vuckovic, D. and Boe, J. (1994) Why do our patients die of active tuberculosis in the era of effective therapy? Tuberculosis and Lung Disease, 75, 329-333. doi:10.1016/0962-8479(94)90077-9

[18] Franke, M.F., Appleton, S.C., Bayona, J., Arteaga, F., Palacios, E., Llaro, K., Shin, S.S., Becerra, M.C., Murray, M.B. and Mitnick, C.D. (2008) Risk factors and mortality associated with default from multidrug-resistant tuberculosis treatment. Clinical Infectious Diseases, 46, 1844-1851. doi:10.1086/588292

[19] Akintunde, E.O., Shokunbi, W.A. and Adekunle, C.O. (1995) Leucocyte count, platelet count and erythrocyte sedimentation rate in pulmonary tuberculosis. African Journal of Medicine and Medical Science, 24, 131-134. PMid:8669390

[20] Barnes, P.F. (2003) Immunotherapy for tuberculosis: wave of the future or tilting at windmills? American Journal of Respiratory and Critical Care Medicine, 168, 142-143. doi:10.1164/rccm.2305001

[21] Churchyard, GJ, Kaplan, G, Fallows, D, Wallis, RS, Onyebujoh, P. and Rook, GA. (2009) Advances in immunotherapy for tuberculosis treatment. Clinical Chest Medicine, 30, 769-782. doi:10.1016/j.ccm.2009.08.009

[22] Dheda, K., Schwander, S.K., Zhu, B., van Zyl-Smit, R.N. and Zhang, Y. (2010) The immunology of tuberculosis: from bench to bedside. Respirology, 15, 433-450. doi:10.1111/j.1440-1843.2010.01739.x

[23] Grange, J.M., Brunet, L.R. and Rieder, H.L. (2011) Immune protection against tuberculosis-when is immunotherapy preferable to vaccination? Tuberculosis, 91, 179-185. doi:10.1016/j.tube.2010.12.004

[24] Silin, D.S., Lyubomska, O.V., Ershov, F.I., Frolov, V.M. and Kutsyna, G.A. (2009) Immunomodulators with interferon inducing properties. Current Pharmaceutical Design, 15, 1238-1247. doi:10.2174/138161209787846847

[25] Arjanova, O.V., Prihoda, N.D., Sokolenko, N.I., Yurchenko, L.V., Vihrova, L.A., Pylypchuk, V.S., Frolov, V.M. and Kutsyna, G.A. (2009) Impact of adjunct immunotherapy with multi-herbal supplement Dzherelo (Immunoxel) on treatment outcomes in end-stage TB/HIV patients. Journal of Antivirals and Antiretrovirals, 1, 86-88. doi:10.4172/jaa.1000013

[26] Stanford, J., Stanford, C. and Grange, J. (2004) Immunotherapy with Mycobacterium vaccae in the treatment of tuberculosis. Frontiers in Bioscience, 9, 1701-1719. doi:10.2741/1292 